\title{
Full Mouth Rehabilitation of Adult Rampant Caries with Pragmatic Approach
}

\author{
1P Sindhu Padmanabha, 2Patrick T Arul, ${ }^{3}$ IB Geeta
}

\section{ABSTRACT}

Aim: The aim of this article is full mouth rehabilitation of adult rampant caries with a pragmatic approach.

\begin{abstract}
Background: Dentistry has evolved from treating pain and oral diseases to improving esthetics and the overall look and appeal of an individual. Rampant caries are the nightmares of every individual, which are even more grossly accentuated in adults when compared with children. It can lead to emotional imbalance and the near death of a person's confidence. The prognosis of the treatment depends upon the age of the patient, extent of decay, cooperation of the patient, and the patient's motivation toward dental treatment. Herein, the pragmatic approach comes into play, by focusing on what is still left in the patient's arsenal. This simply means the esthetics of the patient's dentition has been improved from the original appearance, but may not be perceived as "dental perfection," which can be accomplished through adhesive restorations.
\end{abstract}

Case report: A 38-year-old female patient reported to the department with rapid widespread decay in her upper and lower teeth for 2 years, after her second pregnancy and was mainly concerned with esthetics in her anterior dentition. The treatment included extraction of hopeless teeth irt \#16, 26, 46, 15, 22 and root canal treatment reinforced with fiber post \#11, 12, 13, 14, $21,23,31,32,33,41,42,43,44,45,46$ followed by composite restorations to enhance the esthetics, and the missing teeth were replaced with removable partial dentures.

Conclusion: The esthetic result achieved may not conform to the highest dental perfection, but represents an effective way of protecting the teeth from further tooth structure loss, while effecting an improvement in patient-perceived esthetics. This is the concept of pragmatic esthetics.

Clinical significance: Composite resin restorations represent an effective way of enhancing the esthetics and conservation of the remaining sound tooth structure for rampant caries.

Keywords: Adult rampant caries, Case report, Composites, Full mouth rehabilitation, Pragmatic approach.

How to cite this article: Padmanabha PS, Arul PT, Geeta IB. Full Mouth Rehabilitation of Adult Rampant Caries with Pragmatic Approach. J Oper Dent Endod 2017;2(2):88-92.

\footnotetext{
${ }^{1,2}$ Postgraduate Student (Final Year), ${ }^{3} \mathrm{Head}$

${ }^{1-3}$ Department of Conservative Dentistry and Endodontics RajaRajeswari Dental College \& Hospital, Bengaluru, Karnataka India

Corresponding Author: P Sindhu Padmanabha, Postgraduate Student (Final Year), Department of Conservative Dentistry and Endodontics, RajaRajeswari Dental College \& Hospital Bengaluru, Karnataka, India, Phone: +919008456389, e-mail: sindhu8903@gmail.com
}

Source of support: Nil

Conflict of interest: None

\section{BACKGROUND}

Dentistry has evolved over the past 50 years from being primarily a health service to a hybrid profession, ${ }^{1}$ where not only pain and oral disease are treated, but elective esthetic services are increasingly being provided, ${ }^{2}$ often at the request of the patient. The social norms, expectations, and the influence of the media have resulted in the quest for achieving an enhanced smile.

Dentistry's image in modern times and the media has undergone an gargantuan change in recent years, ${ }^{1}$ having been propelled out of the "age of amputation" and into the "age of augmentation." 3 This has been largely due to the widespread use of dental adhesive technology introduced in the 1950s. It has been proposed that dentists will continue to experience a growing demand for their services, largely on the strength of patients' desires for better-looking smiles. ${ }^{4}$

Dental caries is an infectious multifactorial disease and its aggressive form is termed "rampant caries" and is more prevalent in children than in adults. In adults, it occurs after the age of 16 and is also known as "adult severe caries." Leading causes have been pointed to emotional imbalance, excessive craving for sweets and snacks, reduced salivary flow, and a reduced tooth remineralization response. ${ }^{5}$ These cases are treated with full crowns or extractions with replacement by prosthesis. Such extensive procedures were carried out to render long-term benefits, but resulted in loss of the remaining sound tooth structure. Herein starts the debate for the concept of pragmatic esthetics, i.e., the appearance of teeth is made as good as it can be without any significant destruction to the tooth substance. ${ }^{6}$ Though patient satisfaction may be achieved, the esthetics may not conform to the highest dental perfection.

This concept of pragmatic esthetics will be illustrated with a case report in which the esthetics of the patient's anterior dentition was poor. The treatment goal was to achieve improved esthetics with minimal loss of tooth structure. The direct composite restorations with minimal costs in these taxing economic times can be considered as gainful for the patient with added benefits of preserving their valuable sound tooth structure. ${ }^{6}$ 


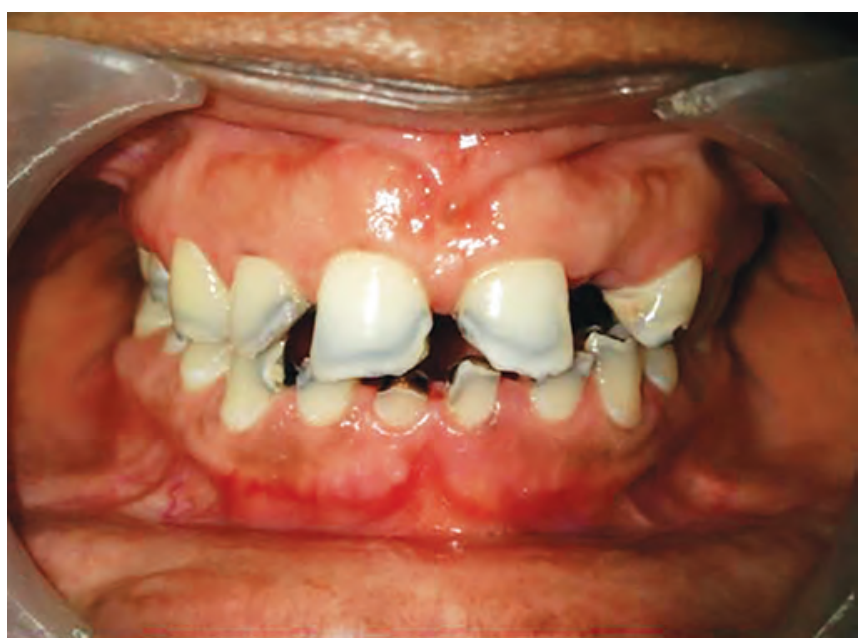

Fig. 1: Preoperative picture showing anterior teeth affected by caries

\section{CASE REPORT}

A 38-year-old female patient reported to the Department of Conservative Dentistry and Endodontics complaining of rapid spreading decay in the upper and lower teeth with major concern for esthetics in her anterior dentition. Evaluation of patient's medical history revealed no evident signs or symptoms of any systemic disease. Past dental history revealed that the patient had noticed a sudden onset and rapid decay of the maxillary and mandibular anterior teeth about 2 years ago during her second pregnancy. Routine dental visits included uneventful extractions of severely damaged and nonrestorable teeth. The patient reported no history of pain or discomfort.

Extraoral clinical examination revealed nontender on palpation of temporomandibular joints, muscles of mastication, muscles of facial expression, and associated nonpalpable lymph nodes. Mandibular range of motion was in acceptable limits. Facial appearance did not show any noticeable signs of a collapsed vertical dimension of occlusion. Intraoral clinical findings demonstrated partial edentulism in 16, 26, 47; root stumps in \#15, \#22, and an irregular occlusal plane. Anterior teeth were influenced by soft, burrowing caries to the level of free gingiva (Fig. 1). Generalized mild gingivitis with mild bleeding on probing was noticed on soft tissue and periodontal examination. No mobility or periodontal pockets were elicited on any of the remaining teeth. Radiographic examination demonstrated healthy roots with adequate root length, adequate periodontal and bone support, and a favorable bony trabecular pattern (Fig. 2).

The patient was cooperative and was categorized under "philosophical" category as per House classification of mental attitude. A diagnosis of adult rampant caries was made, and the nature of the disease was noted. Diagnostic impressions were made with alginate (Algitex, Dental products of India, The Bombay Burmah

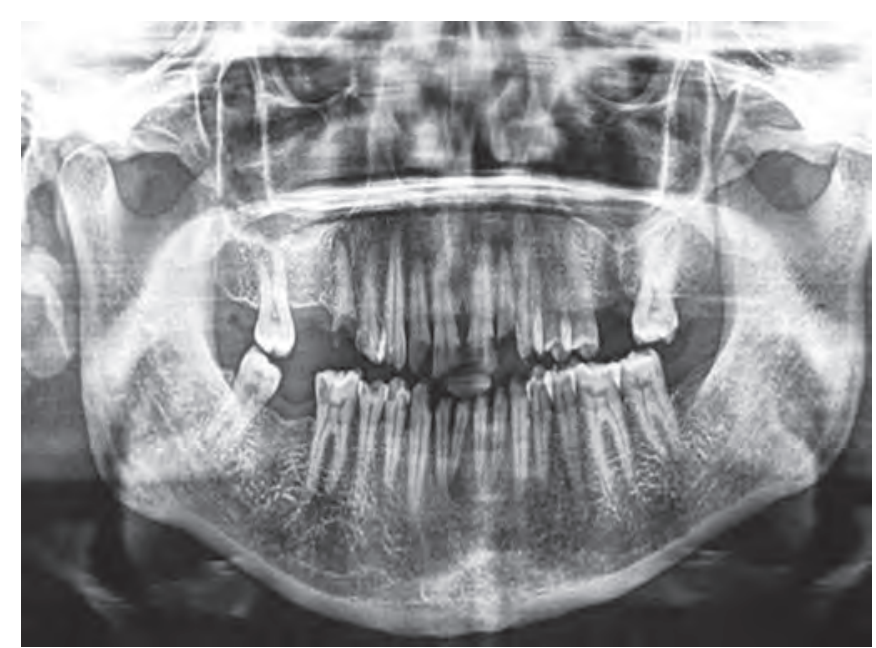

Fig. 2: Preoperative orthopantomogram

Trading Corporation Ltd., Mumbai, India) and the casts were poured with type III stone dental stone (Kalstone, Kalabhai Karson Pvt. Ltd., Mumbai, India). Based on the diagnostic models and clinical findings, an interdisciplinary approach was undertaken and a thorough treatment plan with pros and cons of each treatment and alternatives, such as full ceramic crowns and overdentures were explained to the patient and the patient elected for direct composite restorations. On obtaining the patient's consent, the treatment was initiated. The treatment objective was to arrest the caries and its progression and restoration of the teeth to its natural appearance. The patient was motivated for the treatment, and oral hygiene instructions were given and the benefits of good oral hygiene were emphasized.

The treatment was as follows:

- Root stumps in \#15, \#22 were extracted.

- Oral prophylaxis was done and oral hygiene was emphasized.

- Root canal treatments were carried out in tooth \#11, $12,13,14,21,23,31,32,33,41,42,43,44,45,46$.

- Post space preparation (Fig. 3) etch and rinse (3M ESPE) of the post space (Fig. 4) followed by reinforcement with prefabricated fiber posts (Tenax Fiber Trans, Coltene Whaledent Pvt. Ltd. 235 ascot Parkway, Ohio, USA) luted (Panavia F) and light cured (Fig. 5) of tooth \#11, 12, 13, 14, 21, 23, 31, 32, 33, 41, 42, 43, 44, 45, 46 and the composite restoration foundation buildup were done with nanohybrid composite resin $\left(\right.$ Tetric $^{\circledR}$ N-Ceram, Ivoclar Vivadent AG, FL-9494, Schaan, Liechtensein) (Fig. 6).

- Removable partial denture in tooth \#15, 16, 22, 26, 47 (Figs 7 and 8).

\section{DISCUSSION}

Rampant caries is of acute onset and a rapidly progressive disease, leading to functional, esthetic, and psycho- 


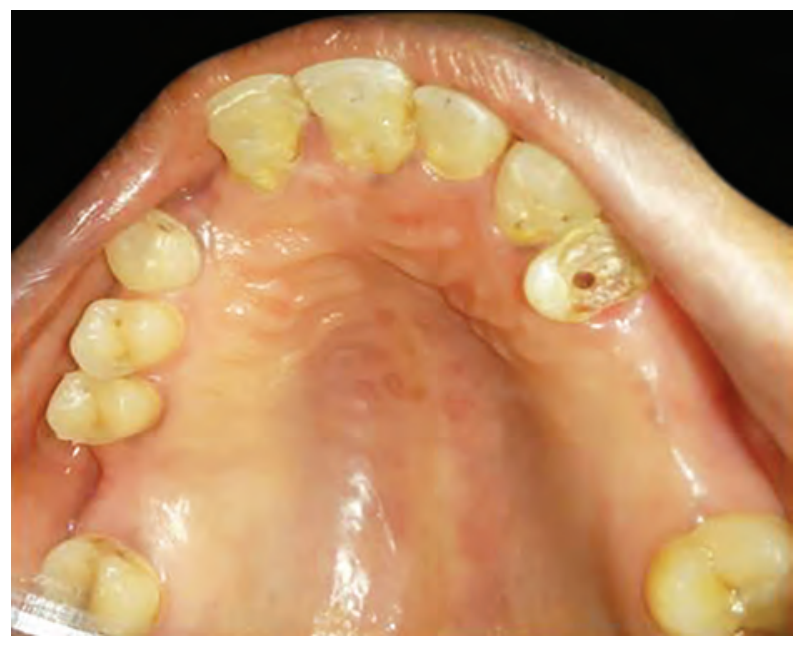

Fig. 3: Prepared post space

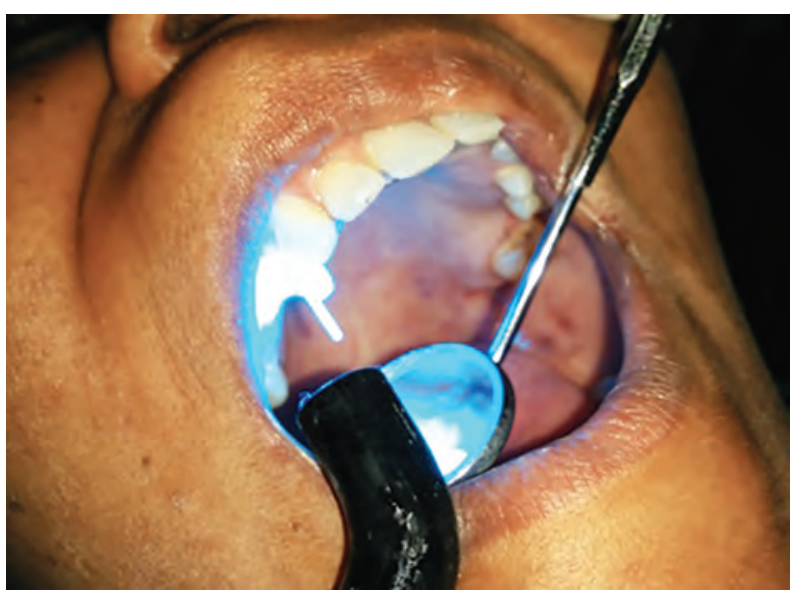

Fig. 5: Light curing of the fiber post

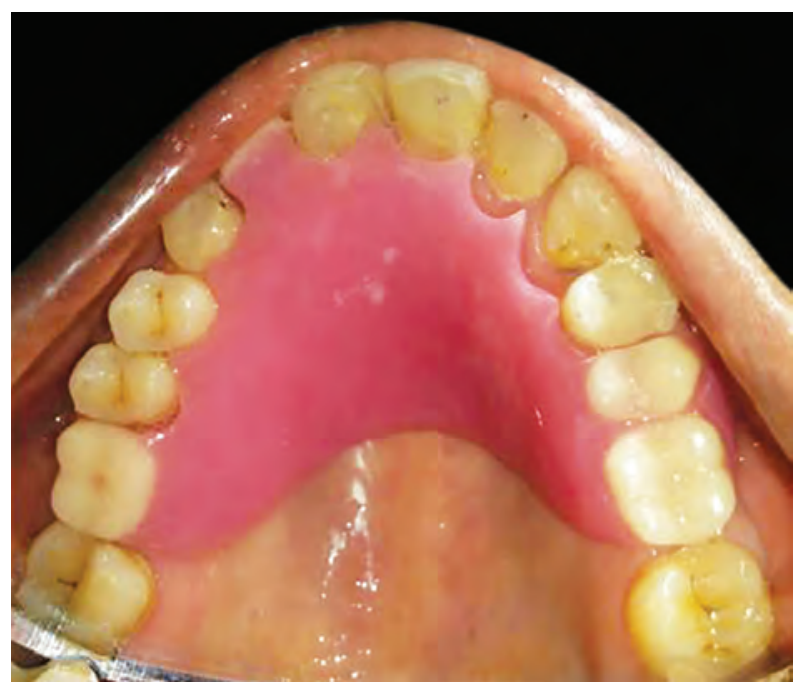

Fig. 7: Removable prosthesis in maxilla

logical disturbances of the patient. It has been defined by Massler" as "a suddenly appearing, widespread, rapid burrowing type of caries, resulting in early involvement of the pulp and affecting those teeth usually regarded as immune to ordinary decay." Winter ${ }^{8}$ termed rampant

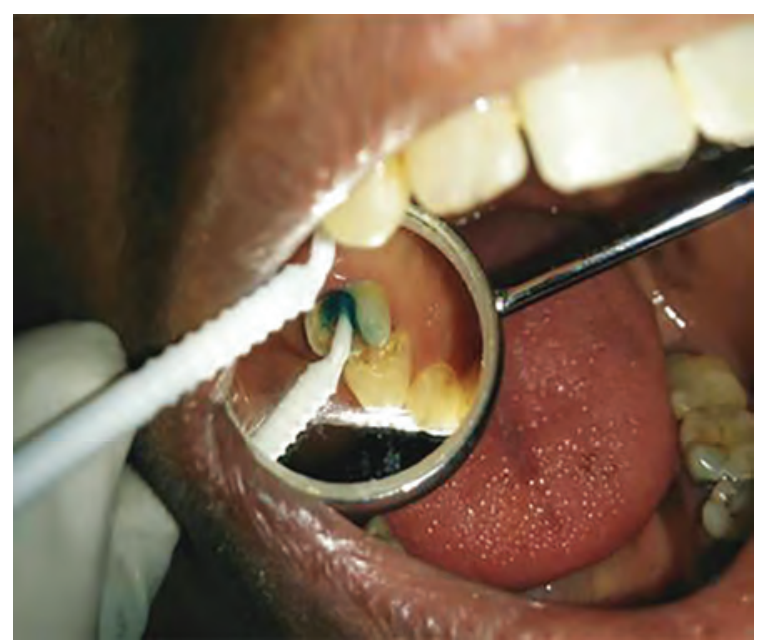

Fig. 4: Post space etching

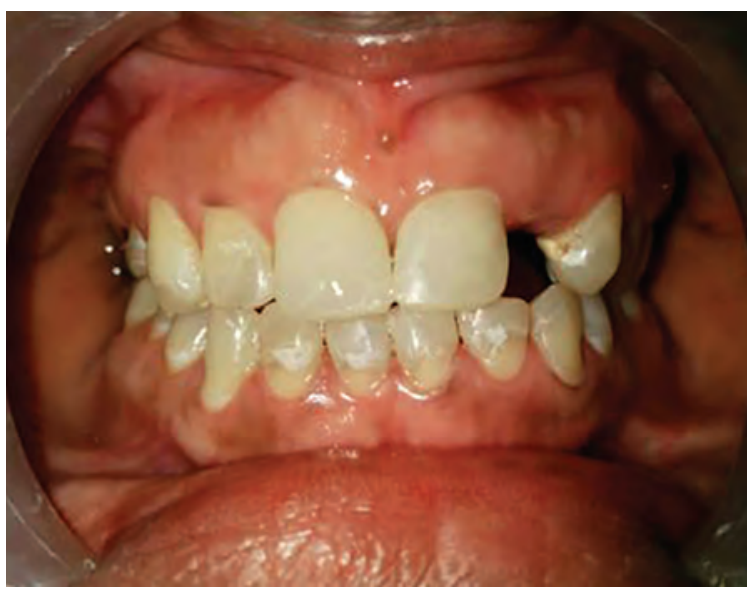

Fig. 6: Direct composite restoration

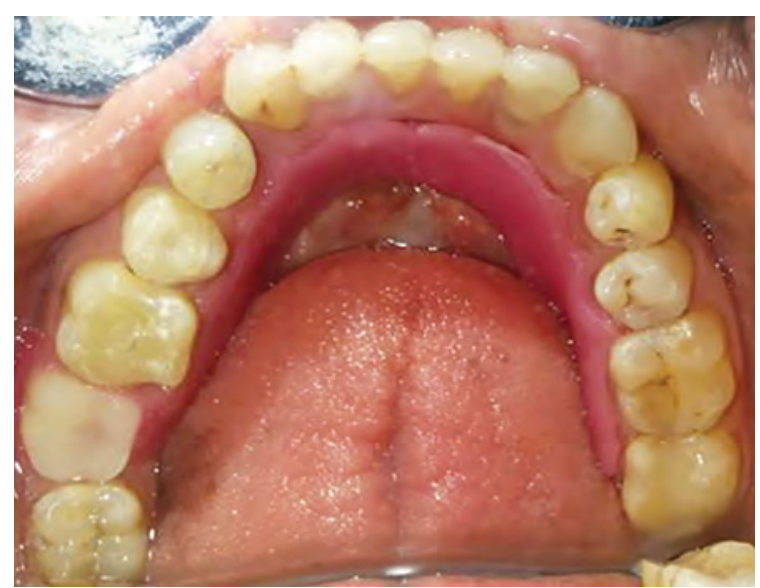

Fig. 8: Removable prosthesis in mandibular arch

caries as caries of acute onset involving many or all teeth in areas that are not susceptible and is associated with rapid destruction of the crowns with frequent involvement of the dental pulp. The incidence of rampant caries is high in children and young adolescents and less in 


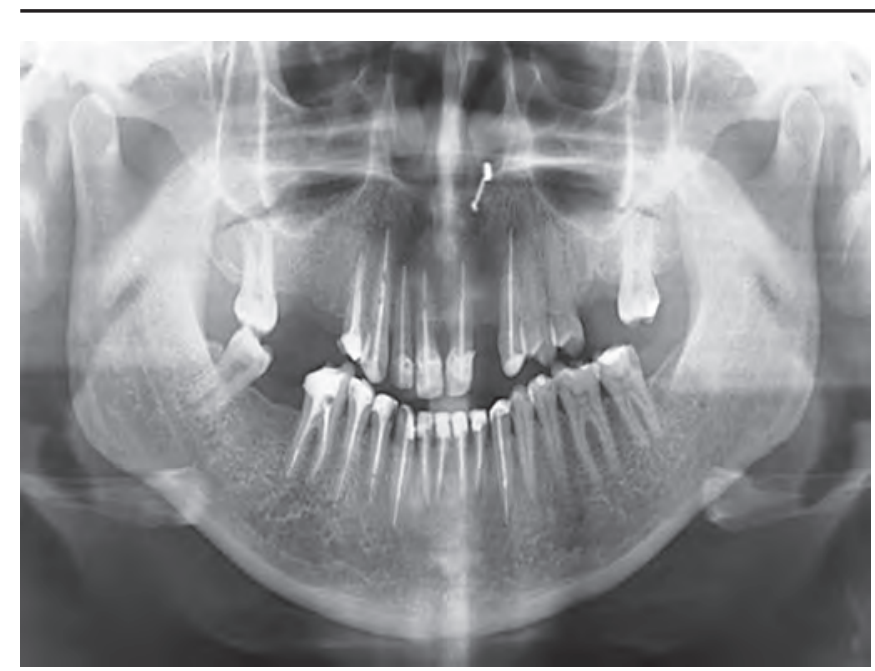

Fig. 9: Postoperative orthopantomogram

adults. The causative factors can be the imbalance in the oral environment, inadequate dietary habits, emotional stress, and inadequate access to the dental care. In this case, the risk factor could be attributed to be pregnancy as explained in a study by Lallam and Decup. ${ }^{9}$ The type of treatment solely relies on the patient's inclination toward dental treatment, level of decay, age, and cooperation of the patient. ${ }^{10}$

The focus of any dental treatment is to facilitate the readaptation of the damaged dentition to a healthy state. The treatment planning in dentistry usually comprises of three phases: Biological, restorative, and esthetics. Biological aspects include caries susceptibility, periodontal health, endodontic needs, and general oral health. Once biological health is resolved, then the restorations of resulting defects should be considered and finally esthetics would be addressed to provide a pleasing appearance of the teeth.

Chu et $\mathrm{al}^{11}$ suggested minimal intervention dentistry as a new approach for the management of caries in old patients. It involves early diagnosis and treatment, improving the oral environment, reducing the caries risk, reversal of dental caries, and minimal surgical intervention procedures.

Treatment options included adhesive restorations, ${ }^{12,13}$ overdentures, ${ }^{14}$ occlusal overlay splint, ${ }^{15,16}$ removable partial denture, ${ }^{17}$ fixed partial denture, or crowns and implants. ${ }^{18}$

Due to the reduced amount of available tooth structure with no loss of vertical dimension and patient's economic and time constraints, root canal treatments of the deep carious teeth were done by reinforcement of the same teeth with prefabricated glass fiber posts (Fig. 9) followed by restorations with direct composite resin. The partially edentulous areas were replaced with removable partial denture and the function and esthetics of the patient's dentition were achieved (Fig. 10).

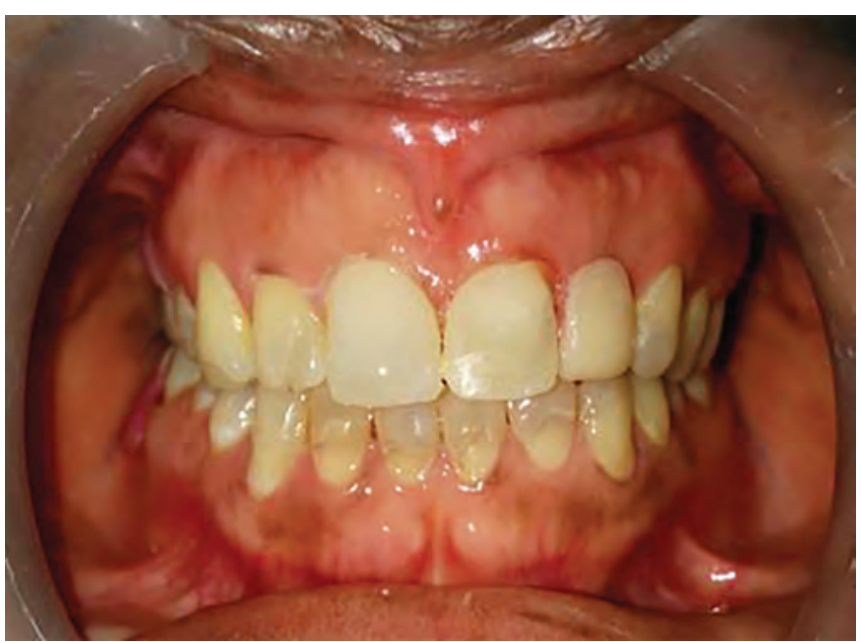

Fig. 10: Restoration of function and esthetics

This is the concept of pragmatic esthetics. Pragmatic means "relating to fact" and is defined in the Oxford English Dictionary ${ }^{19}$ as dealing with the things sensibly and realistically in a way, i.e., based on practical rather than theoretical considerations. Many case reports have mentioned treatment of rampant caries with full crowns at the cost of the tooth structure to achieve esthetics. The use of composite restorations represents a biologically sound treatment modality for the management of adult rampant caries. These treatments offer high degrees of patient satisfaction ${ }^{20}$ within the biological principles of pulp and periodontal management. Though the treatment achieved esthetics and preserved the tooth from further loss, it had its shortcomings of frequent finishing and polishing. Patient accommodation to the technique was good and similar results were obtained with many authors. ${ }^{21,22}$

\section{CONCLUSION}

The concept of pragmatic esthetics was achieved by direct composite restorations though it did not conform to the highest dental perfection procured by full crowns.

\section{CLINICAL SIGNIFICANCE}

Composite resin restoration represents an effective way of enhancing the esthetics with an added benefit of conservation of the remaining sound tooth structure for rampant caries and worn-out teeth.

\section{REFERENCES}

1. Mandel ID. The image of dentistry in contemporary culture. J Am Dent Assoc 1998 May;129(5):607-613.

2. Priest G, Priest J. Promoting esthetic procedures in the prosthodontic practice. J Prosthodont 2004 Jun 1;13(2):111-117.

3. Golub-Evans J. Unity and variety: essential ingredients of a smile design. Curr Opin Cosmet Dent 1994:1-5.

4. Christensen GJ. Are prosthodontics a vital part of dentistry. J Am Dent Assoc 2002 May 1;133(5):647-648. 
5. Varghese S, Bhat V, Devi LS. Adult rampant caries: a clinical report. Indian J Oral Sci 2016 Jan 1;7(1):42.

6. Burke FJ, Kelleher MG, Wilson N, Bishop K. Introducing the concept of pragmatic esthetics, with special reference to the treatment of tooth wear. J Esthet Restor Dent 2011 Oct 1;23(5):277-293.

7. Massler JN. Teenage caries. J Dent Child 1945;12;57-64.

8. Winter GB, Hamilton MC, James PM. Role of the comforter as an aetiological factor in rampant caries of the deciduous dentition. Archives of Disease in Childhood. 1966 Apr;41(216):207.

9. Lallam C, Decup F. Minimal intervention dentistry II: part 2. Management of caries and periodontal risks in general dental practice. Br Dent J 2014 Feb 21;216(4):179-185.

10. Plutzer K, Spencer AJ. Efficacy of an oral health promotion intervention in the prevention of early childhood caries. Community Dent Oral Epidemiol 2008 Aug 1;36(4):335-346.

11. Chu BF, Zhang Y, Liu HC. Minimal intervention dentistry: a vision of caries management for older patients. II. Hua $X_{i}$ Kou Qiang Yi Xue Za Zhi 2010 Feb;28(1):9-12.

12. Soares CJ, Pizi EC, Fonseca RB, Martins LR, Neto AJ. Direct restoration of worn maxillary anterior teeth with a combination of composite resin materials: a case report. J Esthet Restor Dent 2005 Mar 1;17(2):85-91.

13. Robinson S, Nixon PJ, Gahan MJ, Chan MF. Techniques for restoring worn anterior teeth with direct composite resin. Dent Update 2008 Oct;35(8):551-552.

14. Goud A, Deshpande S. Prosthodontic rehabilitation of dentinogenesis imperfecta. Contemp Clin Dent 2011 Apr;2(2):138-141.
15. Koksal T, Dikbas I, Kazaoglu E. Alternative restorative approach for treatment of patient with extremely worn dentition. N Y State Dent J 2009 Aug;75(5):52-55.

16. Song MY, Park JM, Park EJ. Full mouth rehabilitation of the patient with severely worn dentition: a case report. J Adv Prosthodont 2010 Sep 1;2(3):106-110.

17. Ganddini MR, Al-Mardini M, Graser GN, Almog D. Maxillary and mandibular overlay removable partial dentures for the restoration of worn teeth. J Prosthet Dent 2004 Mar 31;91(3):210-214.

18. Bencharit S, Schardt-Sacco D, Border MB, Barbaro CP. Full mouth rehabilitation with implant-supported prostheses for severe periodontitis: a case report. Open Dent J 2010 Aug 13;4(1):165-171.

19. The Oxford Dictionary. Oxford: Oxford University Press; 2000.

20. Hemmings KW, Darbar UR, Vaughan S. Tooth wear treated with direct composite restorations at an increased vertical dimension: results at 30 months. J Prosthet Dent 2000 Mar;83(3):287-293.

21. Redman CD, Hemming KW, Good JA. The survival and clinical performance of resin-based composite restorations used to treat localized anterior tooth wear. Br Dent J 2003 May 24;194(10):566-572.

22. Gow AM, Hemmings KW. The treatment of localized anterior tooth wear with indirect Art glass restorations at increased occlusal vertical dimension. Results after 2 years. Eur J Prosthodont Rest Dent 2002 Sep;10(3):101-105. 